\title{
How can we realise the potentially large public health benefit of screening for type 2 diabetes mellitus in south Asians?
}

\author{
K. Stronks • I. G. M. van Valkengoed
}

Received: 22 April 2011 / Accepted: 13 June 2011 /Published online: 16 July 2011

(C) The Author(s) 2011. This article is published with open access at Springerlink.com

Keywords Ethnicity. Oral glucose tolerance test .

Response · Screening $\cdot$ South Asian · Type 2 diabetes

\section{Abbreviations \\ ADDITION \\ Anglo-Danish-Dutch study of Intensive \\ Treatment In peOple with screeN \\ detected diabetes in primary care}

The increasing incidence of type 2 diabetes and associated morbidity poses an enormous challenge for public health. The implementation of prevention programmes directed towards individuals at high risk might reduce overall morbidity and thus the cost to the healthcare system [1]. A large benefit in this regard might be achieved by targeting south Asian immigrant populations living in Europe, since various reports have suggested that these populations not only have an increased risk of type 2 diabetes, but are also more likely to have other cardiovascular risk factors [2-5]. In addition, type 2 diabetic patients of south Asian origin are at a higher risk than white populations of developing diabetes-related morbidity [6-8].

While immigrants of south Asian origin are thus an important target group for active screening and preventive interventions, data on the feasibility and effectiveness of prevention programmes in these populations are scarce. Issues that need to be explored include strategies to promote the uptake of screening, the prevalence of

\section{K. Stronks $(\bowtie) \cdot$ I. G. M. van Valkengoed}

Department of Public Health, Academic Medical Center,

University of Amsterdam,

Meibergdreef 15,

1105 AZ Amsterdam, The Netherlands

e-mail: k.stronks@amc.uva.nl undetected diabetes mellitus and other metabolic risk factors in various settings, the risk of morbidity associated with undetected disease, and targeted preventive interventions and their potential effectiveness in the south Asian groups as compared with the white population. The study by Webb et al. in this issue of Diabetologia [9], reports on the results of one of the few ongoing studies in Europe to address some of these different aspects [10-13]. This study is based on data from the UK-based Leicester arm of the Anglo-Danish-Dutch study of Intensive Treatment In peOple with screeN detected diabetes in primary care (ADDITION-Leicester) and focuses on white Europeans and on south Asians who were predominantly of Indian origin [10].

In this study, the response to an invitation for screening by OGTT through community practices appeared to be lower among the south Asian population than among the white European population (13\% vs $26 \%)$, despite the employment of culturally sensitive promotional activities. The odds of undetected type 2 diabetes or impaired glucose regulation was twice as high among the screened south Asians as among the white Europeans (2.30 [95\% CI 1.68, 3.16] for type 2 diabetes and 2.08 [95\% CI 1.38, 3.14] for impaired glucose tolerance and impaired fasting glucose [age- and sex-adjusted]). In addition, Webb et al. confirmed the high cardiovascular burden among participants with screen-detected type 2 diabetes or impaired glucose regulation, and modelled the absolute risk reduction that would be achieved by a preventive approach consisting of the prescription of therapies targeting glycaemia, blood pressure and cholesterol. The potential health gain appeared to be substantial, particularly among the south Asian population; this applied not only to those with type 2 diabetes, but also to those with impaired glucose regulation. 
The study by Webb et al. contributes to the evidence base for type 2 diabetes screening. It clearly illustrates the potential public health impact among south Asian immigrant populations. However, several issues have to be taken into account when interpreting the estimated health gain.

First, those who did participate might be a relatively healthy or health conscious subset of the south Asian population, the so-called worried well. For example, in contrast to the higher prevalence of overweight and central obesity in south Asians compared with Europeans as observed in a previous study (with overweight defined as BMI $\geq 23 \mathrm{~kg} / \mathrm{m}^{2}$ for the south Asian population, and BMI $\geq 25 \mathrm{~kg} / \mathrm{m}^{2}$ for the Europeans) [14], the participants of south Asian origin in the study of Webb et al. appeared relatively healthy as they had a lower waist circumference than the participants of white European origin. On the other hand, medication use for other cardiovascular risk factors was already higher among south Asian participants during the screening than among white Europeans [9]. Without data on those who did not participate, it is difficult to establish the presence and direction of the possible bias owing to selective participation.

Second, type 2 diabetes among south Asian populations, in general, seem to occur earlier than in European populations, as is illustrated by the relatively higher prevalence in younger age groups [5]. While the ADDITION-Leicester study applied a lower age range for the south Asian population (25 years or older instead of 40 years), the younger age group was excluded from the analyses [9]. Including younger age groups in screening programmes may further increase the impact.

Third, it could be questioned whether the ETHRISK calculator, used to estimate the 10 year cardiovascular risk, accurately reflects the burden of disease in south Asian populations. Although the ETHRISK equation was calibrated using register-based data, the equation has not been validated because of a lack of prospective data among south Asians [15]. The currently reported estimates reflect differences in the baseline risk and the distribution of risk factors between populations, but perhaps not the possible differences in the 10 year cardiovascular risk associated with a certain risk factor between populations. These differences are not unlikely as reports have, for instance, suggested differences in the risk of developing diabetes-related morbidity between persons of south Asian and European origin [7]. This could greatly affect the estimations of the potential risk reduction that can be achieved. Without adequate prospective data, it is difficult to determine whether the estimations as given by Webb et al. are a correct reflection or an under- or overestimation of the actual burden of disease.

Although, according to these findings, the potential health gain of screening for type 2 diabetes among south
Asian populations seems enormous, the study of Webb et al. also raises a number of important points regarding the optimal design for such a screening programme. These points should be taken into consideration before any attempt to implement a systematic screening programme is made.

The first relates to the successful recruitment of south Asian populations in screening programmes. In general, previous studies have shown that interventions targeted towards the general population often do not reach nonWestern ethnic minorities or appear to be less effective in these populations $[16,17]$. In the ADDITION-Leicester study, the investigators tried to make the recruitment process culturally sensitive by using appropriate promotions, publicity and screening locations. Nevertheless, the response to the invitation for screening was low among the south Asian population, suggesting that the content of the intervention should perhaps be further adapted or that different methods of recruitment should be used depending on the ethic group being targeted. For example, in a study we found that, besides culturally adapting the materials used, personal contact in the form of telephone reminders instead of written reminders greatly enhanced participation (I. G. M. van Valkengoed, K. Stronks, unpublished results). In addition, one might hypothesise that screening for diabetes by measuring the fasting plasma glucose level and $\mathrm{HbA}_{1 \mathrm{c}}$ might be more attractive to potential participants than screening using an OGTT and therefore produce a higher response. In this respect, it should be mentioned that two trials aimed at evaluating the effect of a culturally targeted lifestyle intervention among populations of south Asian origin are under way that will be able to report on the effect of targeted strategies for OGTT-based and nonOGTT-based screening of type 2 diabetes and impaired glucose regulation $[11,12]$.

Second, the health gain achieved after a successful screening programme will depend on the availability of an effective intervention. Many available interventions have not been targeted to and evaluated among migrant populations $[18,19]$. Developing and evaluating targeted interventions is of the utmost importance as ethnic differences in the effectiveness of interventions have been reported previously. A well known example is the difference in the effectiveness of drug treatment for hypertension among African origin vs white European origin populations [20].

Third, there is clear lack of information about the risk of diabetes-related morbidity among south Asian populations. Prospective research into the risk of disease among south Asians with various degrees of glucose abnormality is necessary in all age groups. Depending on this risk assessment, the criteria for screening may have to be adapted (e.g. age may have to be lowered) for this 
population and specific interventions may have to be made available to a larger number of people (e.g. to those with impaired glucose regulation, not just those with type 2 diabetes).

Finally, we consider it important that these points are investigated in different settings; that is, among south Asian populations living in different European countries. The different experiences and the variation in contexts will likely provide valuable insights for further refining the design and will take screening one step closer towards implementation.

To summarise, Webb et al. confirm the potentially large public health impact of screening for type 2 diabetes mellitus in south Asians. Their study also makes clear, however, that a number of issues have to be addressed before this impact can actually be realised. Both from a public health and a financial perspective, further research in various settings on these issues is warranted. However, even though we may still be one step away from the implementation of targeted screening we should ensure that the lack of evidence is not used as an excuse to withhold interventions from those identified through regular medical practice.

Acknowledgements The authors are funded by the Academic Medical Center of the University of Amsterdam.

Contribution statement K.S. conceptualised and wrote the manuscript, I.G.M.vV. participated in the conceptualisation and contributed to the writing of the manuscript. Both authors approved the final version.

Duality of interest The authors declare that there is no duality of interest associated with this manuscript.

Open Access This article is distributed under the terms of the Creative Commons Attribution Noncommercial License which permits any noncommercial use, distribution, and reproduction in any medium, provided the original author(s) and source are credited.

\section{References}

1. Wareham NJ, Griffin SJ (2001) Should we screen for type 2 diabetes? Evaluation against National Screening Committee criteria. BMJ 322:986-988

2. Bhopal R, Unwin N, White M et al (1999) Heterogeneity of coronary heart disease risk factors in Indian, Pakistani, Bangladeshi, and European origin populations: cross sectional study. BMJ 319:215-220

3. Cappucio FP, Cook DG, Atkinson RW, Strazullo P (1997) Prevalence, detection, and management of cardiovascular risk factors in different ethnic groups in south London. Heart 78:555563

4. Bindraban NR, van Valkengoed IG, Mairuhu G et al (2008) A new tool, a better tool? Prevalence and performance of the Interna- tional Diabetes Federation and the National Cholesterol Education Program criteria for metabolic syndrome in different ethnic groups. Eur J Epidemiol 23:37-44

5. Qiao Q, Hu G, Tuomilehto J et al (2003) Age- and sex-specific prevalence of diabetes and impaired glucose regulation in 11 Asian cohorts. Diabetes Care 26:1770-1780

6. Fischbacher CM, Bhopal R, Rutter MK et al (2003) Microalbuminuria is more frequent in South Asian than in European origin populations: a comparative study in Newcastle, UK. Diabet Med 20:31-36

7. Chandie Shaw PK, Vandenbroucke JP, Tjandra YI et al (2002) Increased end-stage diabetic nephropathy in Indo-Asian immigrants living in the Netherlands. Diabetologia 45:337-341

8. Fischbacher CM, Bhopal R, Povey C et al (2007) Record linked retrospective cohort study of 4.6 million people exploring ethnic variations in disease: myocardial infarction in South Asians. BMC Public Health 7:142

9. Webb DR, Gray LJ, Khunti K et al (2011) Screening for diabetes using an oral glucose tolerance test within a Western multi-ethnic population identifies modifiable cardiovascular risk: the ADDITION-Leicester study. Diabetologia. doi:10.1007/s00125011-2189-2

10. Webb DR, Khunti K, Srinivasan B et al (2010) Rationale and design of the ADDITION-Leicester study, a systematic screening programme and randomised controlled trial of multi-factorial cardiovascular risk intervention in people with type 2 diabetes mellitus detected by screening. Trials 11:16

11. Samsudeen BS, Douglas A, Bhopal RS (2011) Challenges in recruiting South Asians into prevention trials: health professional and community recruiters' perceptions on the PODOSA trial. Public Health 125:201-209

12. Vlaar L, van Valkengoed IGM, Nierkens V, Nicolaou M, Middelkoop B, Stronks K (2010) Design and methods of a targeted diabetes prevention programme for Hindustani Surinamese (DH!AAN), consisting of screening followed by a lifestyle intervention. Eur J Public Health 20(Suppl 1):52-53 (Abstract)

13. Johansen KS, Bjørge B, Hjellset VT, Holmboe-Ottesen G, Råberg M, Wandel M (2010) Changes in food habits and motivation for healthy eating among Pakistani women living in Norway: results from the InnvaDiab-DEPLAN study. Public Health Nutr 13:858867

14. Agyemang C, Kunst A, Bhopal R et al (2011) Dutch vs English advantage in the epidemic of central and generalised obesity is not shared by ethnic minority groups: comparative secondary analysis of cross-sectional data. Int $\mathrm{J}$ Obes (Lond). doi:10.1038/ ijo. 2010.281

15. Brindle P, May M, Gill P et al (2006) Primary prevention of cardiovascular disease: a web-based risk score for seven British black and minority ethnic groups. Heart 92:1595-1602

16. Jepson RG, Harris FM, Platt S, Tannahill C (2010) The effectiveness of interventions to change six health behaviours: a review of reviews. BMC Public Health 10:538

17. Kreuter MW, Wray RJ (2003) Tailored and targeted health communication: strategies for enhancing information relevance. Am J Health Behav 27(Suppl 3):S227-S232

18. Epstein S (2008) The rise of 'recruitmentology': clinical research, racial knowledge, and the politics of inclusion and difference. Soc Stud Sci 38:801-832

19. Mason S, Hussain-Gambles M, Leese B, Atkin K, Brown J (2003) Representation of South Asian people in randomised clinical trials: analysis of trials' data. BMJ 326:1244-1245

20. Agyemang C, Kunst A, Bhopal R et al (2010) A cross-national comparative study of blood pressure and hypertension between English and Dutch South-Asian- and African-origin populations: the role of national context. Am J Hypertens 23:639-648 